University of Nebraska - Lincoln

DigitalCommons@University of Nebraska - Lincoln

Biological Systems Engineering: Papers and

Publications

Biological Systems Engineering

3-2-2021

\title{
Comparative Study of Human Pluripotent Stem Cell-Derived Endothelial Cells in Hydrogel-Based Culture Systems
}

Zhanqi Wang

Fuxing Zuo

Qing Liu

Xuesheng Wu

Qian Du

See next page for additional authors

Follow this and additional works at: https://digitalcommons.unl.edu/biosysengfacpub

Part of the Bioresource and Agricultural Engineering Commons, Environmental Engineering Commons, and the Other Civil and Environmental Engineering Commons

This Article is brought to you for free and open access by the Biological Systems Engineering at DigitalCommons@University of Nebraska - Lincoln. It has been accepted for inclusion in Biological Systems Engineering: Papers and Publications by an authorized administrator of DigitalCommons@University of Nebraska Lincoln. 
Authors

Zhanqi Wang, Fuxing Zuo, Qing Liu, Xuesheng Wu, Qian Du, Yuguo Lei, Zhangmin Wu, and Haishuang Lin 


\title{
Comparative Study of Human Pluripotent Stem Cell-Derived Endothelial Cells in Hydrogel-Based Culture Systems
}

\author{
Zhanqi Wang, ${ }^{\text {II }}$ Fuxing Zuo, ${ }^{\text {TI }}$ Qing Liu, ${ }^{\text {TI }}$ Xuesheng Wu, ${ }^{\text {II }}$ Qian Du, Yuguo Lei, ${ }^{*}$ Zhangmin Wu, ${ }^{*}$ \\ and Haishuang Lin*
}

Cite This: ACS Omega 2021, 6, 6942-6952

Read Online

\section{ACCESS | Llll Metrics \& More | 国 Article Recommendations | Sl Supporting Information}

ABSTRACT: Human pluripotent stem cell (hPSC)-derived endothelial cells (ECs) are promising cell sources for drug discovery, tissue engineering, and studying or treating vascular diseases. However, hPSC-ECs derived from different culture methods display different phenotypes. Herein, we made a detailed comparative study of hPSC-ECs from three different culture systems (e.g., 2D, 3D PNIPAAm-PEG hydrogel, and 3D alginate hydrogel cultures) based on our previous reports. We expanded hPSCs and differentiated them into ECs in three culture systems. Both $3 \mathrm{D}$ hydrogel systems could mimic an in vivo physiologically relevant microenvironment to protect cells from shear force and prevent cell agglomeration, leading to a high culture efficiency and

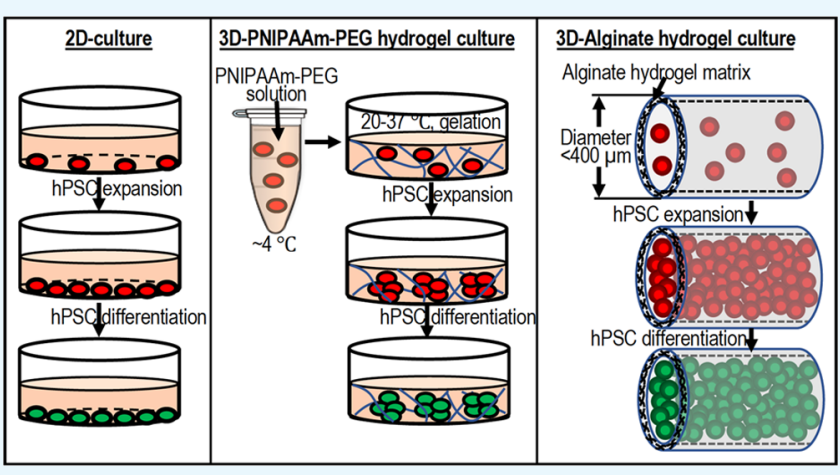
a high volumetric yield. We demonstrated that hPSC-ECs produced from both hydrogel systems had similar results as 2D-ECs. The transcriptome analysis showed that PEG-ECs and alginate-ECs displayed a functional phenotype due to their higher gene expressions in vasculature development, extracellular matrix, angiogenesis, and glycolysis, while 2D-ECs showed a proliferative phenotype due to their higher gene expressions in cell proliferation. Taken together, both PEG- and alginate-hydrogel systems will significantly advance the applications of hPSC-ECs in various biomedical fields.

\section{INTRODUCTION}

Endothelial cells (ECs), which play an important role in normal vascular functions and a variety of vascular diseases, ${ }^{1,2}$ are promising cell sources for drug screening, cell therapy, and tissue engineering. ${ }^{3-11}$ However, because of the limited proliferation capability and quick phenotype change during in vitro culturing, obtaining enough primary ECs for basic applications remains very challenging. ${ }^{12-17}$ Human pluripotent stem cells (hPSCs), including human embryonic stem cells (hESCs) ${ }^{18}$ and induced pluripotent stem cells (iPSCs), ${ }^{19,20}$ provide a potential solution to this challenge ${ }^{21}$ due to their unlimited proliferation capability and the ability to differentiate into all somatic cell types of the human body. ${ }^{22,23}$ In particular, patient-derived iPSCs contain the patient's genetic information and could model many human diseases. Currently, the methods of hPSC differentiation into ECs in a 3D suspension $^{21,24-29}$ or $2 \mathrm{D}$ monolayer ${ }^{4,30-33}$ have been established.

Although efficient differentiation protocols of hPSC-ECs have been developed, ${ }^{33-37}$ bioprocesses applying these methods to produce enough hPSC-ECs and functional ECs are still lacking. Current 2D cell culturing (e.g., cell culture well-plate), which has a low cell yield and often displays a proliferative phenotype, ${ }^{38,39}$ is only suitable for preparing small numbers of cells. ${ }^{40,41}$ 3D suspension culturing (e.g., bioreactors) has been widely used to prepare large numbers of cells. However, these studies also revealed significant challenges, ${ }^{23,40-45}$ such as large cell agglomerates due to frequent cell-to-cell interactions (e.g., hPSCs) ${ }^{40}$ and insufficient mass transport leading to low cell production, cell death, and spontaneous differentiation. ${ }^{40}$ Cell culture through agitation could reduce cell agglomeration, but it also generates a shear force leading to significant cell death. ${ }^{40,46,47}$

To address the challenges mentioned above, we previously reported two scalable and high-cell-yield methods for expanding hPSCs. ${ }^{23,48}$ With those two methods, hPSCs are cultured in a 3D PNIPAAm-PEG (3D-PEG) hydrogel and microscale alginate (3D-alginate) hydrogel tubes, followed by EC differentiation. Both hydrogels could protect cells from the shear force in the culture environment and ensure efficient mass transport during the culturing period. Furthermore, the

Received: December 19, 2020

Accepted: February 19, 2021

Published: March 2, 2021 
two hydrogels provide a highly uniform and physiologically relevant microenvironment for hPSC growth. Then, we systemically explored the comparative study of hPSC-ECs from three different culture systems through the following aspects: cell production, cell differentiation, gene expression, and functional properties. We found ECs derived from hPSCs could be produced with high culture efficiency in both hydrogel culture systems. The whole transcriptome analysis showed 3D-PEG-ECs and 3D-alginate-ECs had higher gene expressions in vasculature development, extracellular matrix, and glycolysis, indicating their functional phenotype, while 2DECs had higher gene expressions in cell proliferation, indicating their proliferative phenotype. We also demonstrated that hPSC-ECs made in three culture systems had similar results as hPSC-ECs generated in $2 \mathrm{D}$ culture methods. Taken together, both 3D-PEG- and 3D-alginate-hydrogel systems with high culture efficiency will significantly advance the applications of hPSC-derived ECs in various biomedical fields.

\section{RESULTS}

hPSC Expansion in 2D, 3D-PEG, and 3D-Alginate Culture Systems. The starting cells H9 hESCs were checked and confirmed to be high-quality pluripotent stem cells according to our previous studies. ${ }^{49}$ The detailed method for processing and culturing hPSCs in the 3D-PNIPAAm-PEG hydrogel $^{23}$ and microscale alginate hydrogel tubes ${ }^{48}$ has been reported in our previous publications (Figure 1). The storage modulus $\left(G^{\prime}\right)(\sim 800 \mathrm{~Pa})$ and the optimal concentration $(10 \%)$ of PNlPAAm-PEG $(\sim 800 \mathrm{~Pa})$ for hPSC biology and culture were identified in previous studies, ${ }^{23}$ and the optimal concentration $(1.5 \%)$ of the sodium alginate hydrogel was determined in our previous studies. ${ }^{48}$ Single hPSCs first form small clusters or small colonies after $24 \mathrm{~h}$ when cultured in the three systems, followed by forming a cell sheet or mass in about 3, 5, and 9 days, respectively (Figure 2A). Immunostaining showed that the majority of the cells culturing in the three systems expressed pluripotent stem cell markers including OCT3/4 and NANOG (Figure 2B-D). Live-/dead-cell staining revealed that very few dead cells were observed during the culturing (Figure 2E,F). When we seeded at $1.0 \times$ $10^{6}$ cells $/ \mathrm{mL}$, hPSCs expanded with about 7 -fold expansion to yield $\sim 7 \times 10^{6}$ cells $/ \mathrm{mL}$ on day 3 in the $2 \mathrm{D}$ culture system, about 20 -fold expansion, yielding $\sim 20$ million cells $/ \mathrm{mL}$, on day 5 in the 3D-PEG hydrogel system, and $\sim 480$-fold to yield $\sim 480 \times 10^{6}$ cells $/ \mathrm{mL}$ on day 9 in the $3 \mathrm{D}$-alginate hydrogel system(Figure 2G,H). H9s and iPSCs had similar outcomes according to our previous studies. ${ }^{50,51}$ The results confirm that expanding hPSCs in both hydrogels is robust and reproducible.

Differentiating hPSCs into ECs in Three Systems. An efficient, simple, and quick method reported by Patsch et al., which could generate ECs from hPSCs in 6 days in 2D culturing, ${ }^{4}$ is a great promising method for producing ECs for biomedical applications (Figure 3A). The produced ECs had the cobblestone morphology typical for ECs, according to the protocol mentioned above (Figure 3B). A majority of the hPSC-derived ECs expressed EC markers including PECAM1 and VE-cadherin, as indicated by immunostaining (Figure 3C). Flow cytometry analysis found $>80 \%$ of the cells were CD $31+$ / CD144+ (Figure 3D,E). According to our previous studies, $^{50,51}$ we demonstrated $\sim 13.8 \%$ or $\sim 11 \% \pm 1.8 \%$ was positive for smooth muscle cells markers, SM22A and $\mathrm{CD} 140 \mathrm{~b}$, and no OCT4+ and NANOG+ undifferentiated hPSCs were detected. Expansions of about 16-fold, $1.6 \times 10^{7}$
A

2D-culture

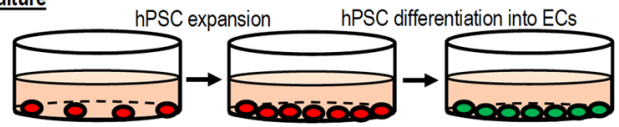

$\mathrm{B}$

3D-PNIPAAm-PEG hydrogel culture

PNIPAAm-PEG

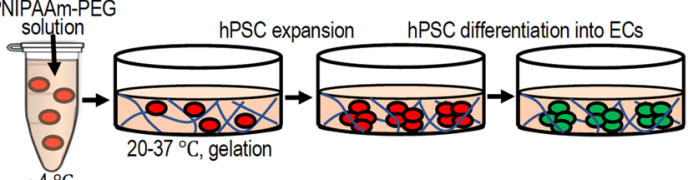

C

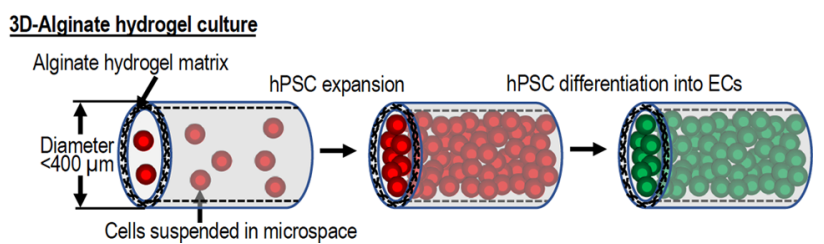

Figure 1. Overview of three culture systems for hPSC expansion and differentiation. (A) Schematic illustration of 2D culture expansion and differentiation of hPSCs. (B) Schematic illustration of the bioprocess of the 3D PNIPAAm-PEG hydrogel for hPSC expansion and differentiation. Single hPSCs $\left(1.0 \times 10^{6}\right.$ cells $/ \mathrm{mL}$ PEG hydrogel $)$ are mixed with a $10 \%$ PNIPAAm-PEG solution at a low temperature [e.g., $4^{\circ}(\mathrm{C})$ ], which forms an elastic hydrogel at $37^{\circ} \mathrm{C}$. Single hPSCs clonally expand into uniform spheroids in the hydrogel in 5 days. Upon cooling to $4{ }^{\circ} \mathrm{C}$, the hydrogel is liquefied, and spheroids are harvested and dissociated into single cells for the next expansion. Once the targeted cell number is reached, hPSCs are differentiated into ECs in the hydrogel. (C) Schematic illustration of the 3D alginate hydrogel for hPSC expansion and differentiation. hPSCs are processed into alginate hydrogel tubes at a low seeding density $(1.0 \times$ $10^{6}$ cells $/ \mathrm{mL}$ alginate hydrogel) and expanded for 9 days to fill the tubes. The day 9 cell masses can be released via dissolving the hydrogel tubes with $0.5 \mathrm{mM}$ EDTA solution, dissociated into single cells with Accutase, and processed into new hydrogel tubes for a second round of expansion. Once the targeted cell number of hPSCs is reached, hPSCs (around day 5) can be differentiated into ECs in the alginate hydrogel.

cells $/ \mathrm{mL}$, in the $2 \mathrm{D}$ system, about 20 -fold, $2 \times 10^{7}$ cells $/ \mathrm{mL}$, in the 3D-PEG hydrogel system, and about 450 -fold, $4.5 \times 10^{8}$ cells $/ \mathrm{mL}$, in the $3 \mathrm{D}$-alginate hydrogel system were produced on day 10 (Figure $3 \mathrm{G}, \mathrm{H})$. H9s and iPSCs had similar outcomes, according to our previous studies. ${ }^{50,51}$ Our results indicated the robustness of the differentiation protocol reported by Patsch et al. ${ }^{4}$

Properties of All ECs Made in Three Systems. Both hydrogel systems provide a physiologically relevant microenvironment for cell growth. Previous reports demonstrated that ECs cultured in a 3D microenvironment displayed different phenotypes and functional properties compared to those cultured in 2D substrates. ${ }^{38,39}$ We thus asked if 3D-PEGECs, 3D-alginate-ECs, and traditional 2D-ECs displayed similar phenotypes, functions, and gene expressions. We found that they had a similar capability of lipid uptake via fluorescently labeled acetylated LDL (Ac-LDL) and microscope imaging (Figure 4A), and they formed similar tubular structures, indicating their similar angiogenic potential through the tube formation assay (Figure 4B-D). 3D-PEG-ECs, 3Dalginate-ECs, and traditional $2 \mathrm{D}-\mathrm{ECs}$ had tight barriers, as indicated by the high trans-endothelial electrical resistance (TEER) value assay. ${ }^{32}$ With the administration of TNF- $\alpha$, IL- 
A

B
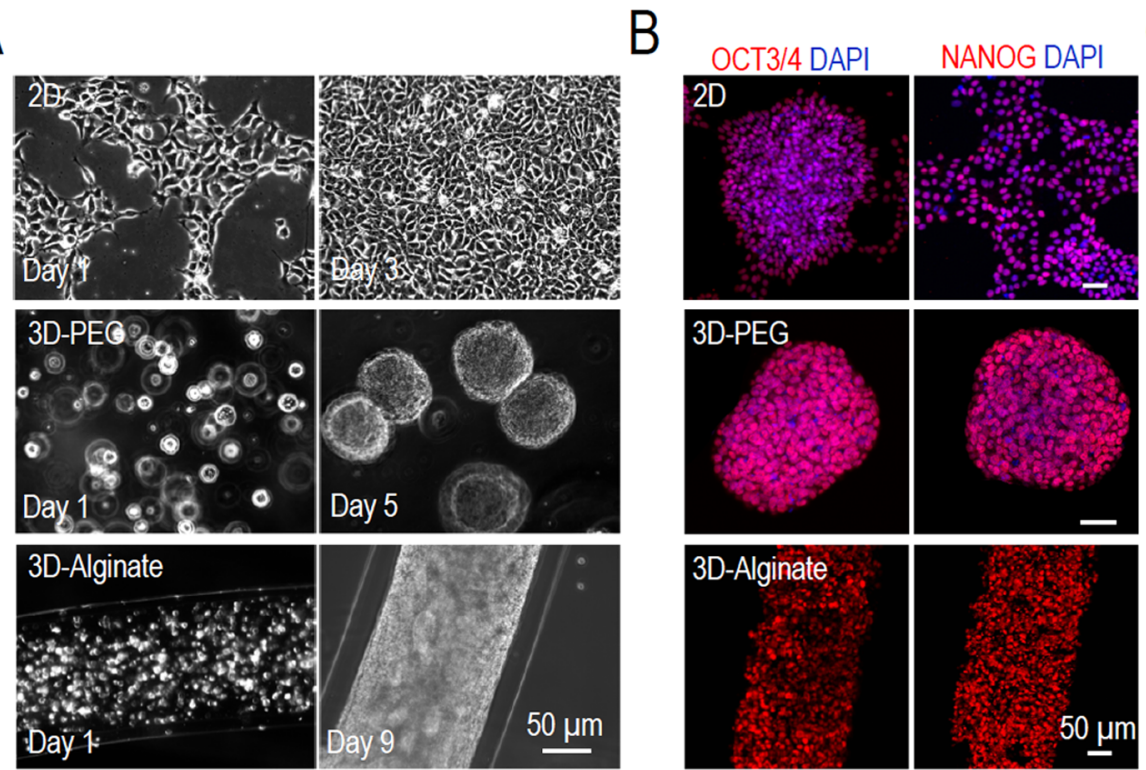

C

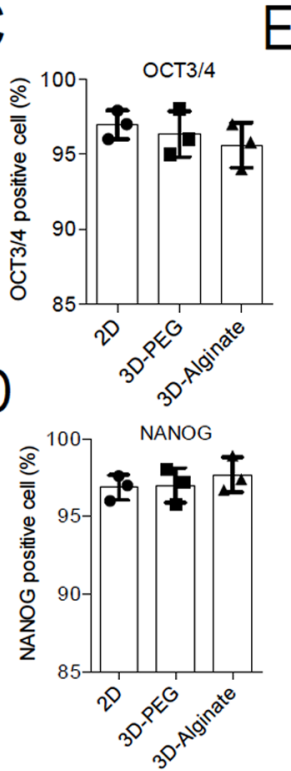

E
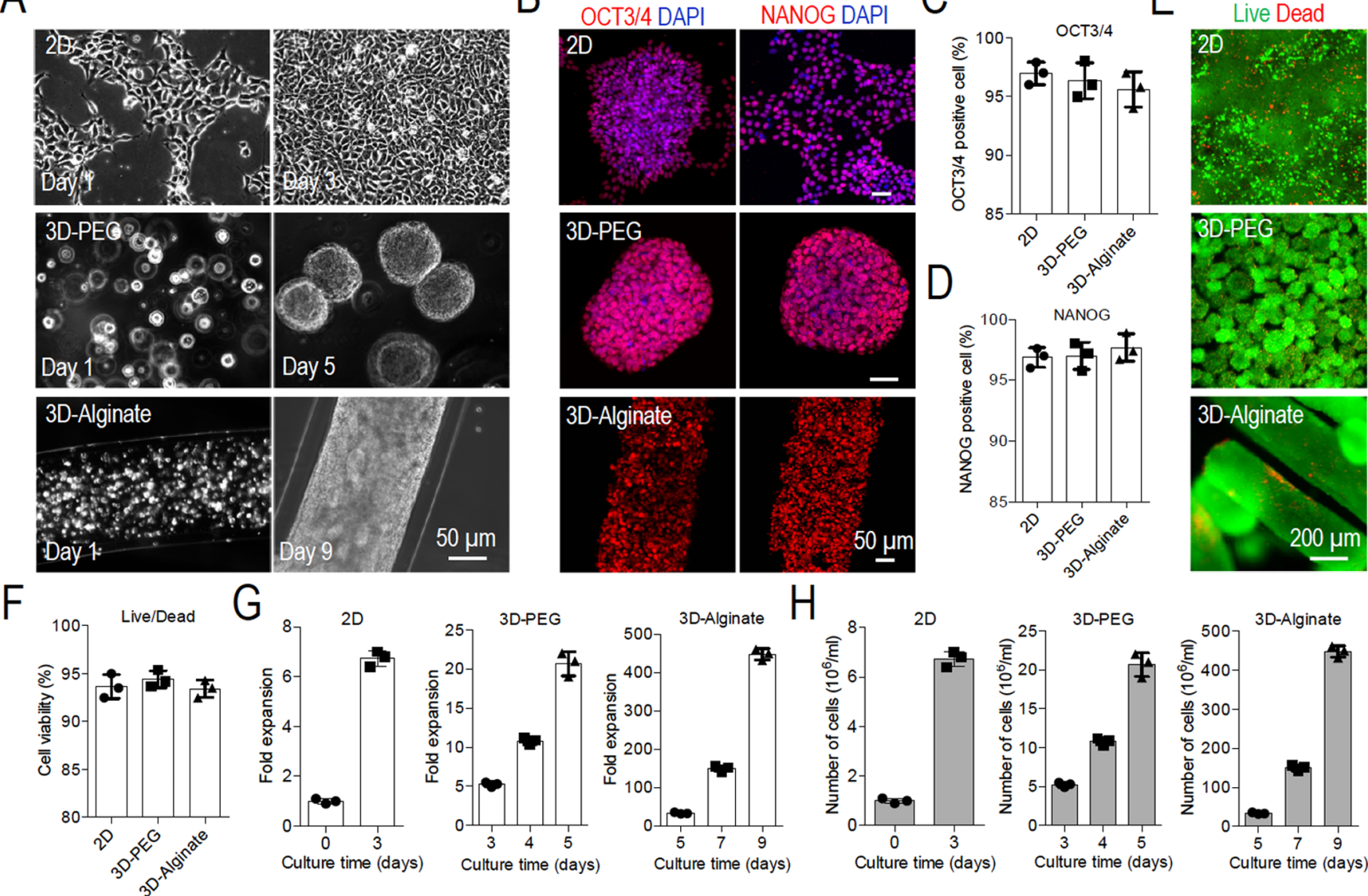

$H$
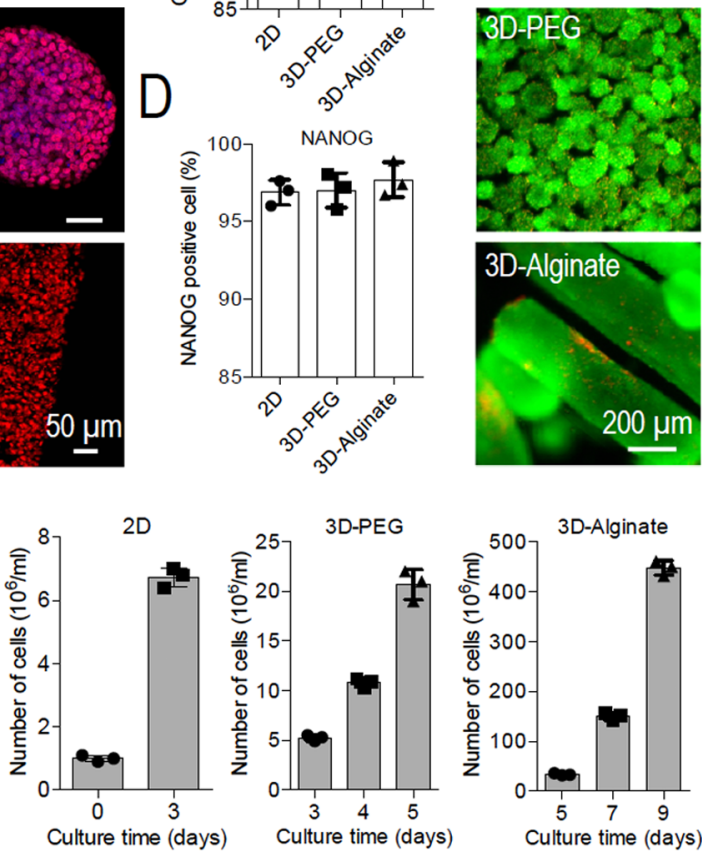

Figure 2. Comparison of hPSC expansion in three culture systems. (A) Phase image of hPSC expansion in 2D, 3D-PEG, and 3D-alginate culture systems. Scale bar, $50 \mu \mathrm{m}$. (B) Immunostaining of the pluripotency markers OCT3/4 and NANOG in 2D, 3D-PEG, and 3D-alginate culture systems. Scale bars, $50 \mu \mathrm{m}$. (C,D) Statistical analysis of OCT3/4- and NANOG-positive cells in 2D, 3D-PEG, and 3D-alginate culture systems. (E,F) Live-/dead-cell staining and statistical analysis of harvested cells from 2D, 3D-PEG, and 3D-alginate culture systems. Scale bar, $200 \mu \mathrm{m}$. $(\mathrm{G}, \mathrm{H})$ When seeded at $1.0 \times 10^{6}$ cells $/ \mathrm{mL}$, about 7 -fold expansion occurs to yield $\sim 7 \times 10^{6}$ cells $/ \mathrm{mL}$ on day 3 in the $2 \mathrm{D}$ culture system; about 5-, 10 -, and 20-fold expansion, yielding $\sim 5,10$, and 20 million cells per milliliter of the hydrogel on days 3,4 , and 5, respectively, is achieved in the 3DPEG culture system; and about $\sim 30-, 150$-, and 480 -fold expansion occur to yield $\sim 30 \times, 150 \times$, and $480 \times 10^{6}$ cells $/ \mathrm{mL}$ on days 5,7 , and 9 , respectively, in the $3 \mathrm{D}$-alginate culture system. Data are represented as mean $\pm \mathrm{SD}(n=3)$.

$1 \beta$, and VEGF-A, the barrier tightness of all ECs was disrupted by a sharp decrease of the TEER values and displayed similar results as the primary human umbilical vein endothelial cells (HUVECs) (Figure 4E). To investigate the angiogenic potential of 3D-PEG-ECs, 3D-alginate-ECs, and 2D-ECs in vivo, we injected ECs from different systems with a Matrigel matrix into the immunodeficient mice. The results revealed the formation of a blood vessel structure in the matrix for all ECs, as indicated by hematoxylin and eosin ( $\mathrm{H} \& \mathrm{E})$-staining and immunostaining, and both hydrogel system-derived ECs displayed a significant increase of mean fluorescence intensity, based on CD31 fluorescent signals (Figure 4F,G). We also used qRT-PCR to quantitatively measure the gene expressions related to ECs, including the surface markers (CD31, CD144, vWF, and CD34), growth factors (VEGFA and VEGFC), and extracellular matrices (FN and COL4A6). Both 3D-PEG-ECs and $3 \mathrm{D}$-alginate-ECs had increased expressions of the EC genes compared with that of 2D-ECs or HUVECs, while alginate-ECs displayed higher gene expressions of CD31, CD144, vWF, VEGFA, and VEGFC (Figure 4H,I). H9s and iPSCs had similar outcomes, according to our previous studies. $^{50,51}$
Transcriptome Analysis of All ECs Generated from Three Systems. Next, we performed the whole transcriptome analysis by sequencing the mRNAs of the undifferentiated $\mathrm{H} 9 \mathrm{~s}$, 2D-ECs, 3D-PEG-ECs, and 3D-alginate-ECs (three biological replicates for each group) to assess differential expression genes (DEGs). Hierarchical clustering analysis showed all hPSC-ECs from three systems clustered closely and displayed very different gene expressions from that of $\mathrm{H} 9 \mathrm{~s}$ (Figure 5A). Principal component analysis (PCA) showed slightly different gene expressions among all ECs, but very different from that of H9s (Figure 5B). The correlation coefficients between 3Dalginate-ECs/2D-ECs, 3D-PEG-ECs/2D-ECs, and 3D-PEGECs/3D-alginate-ECs were $>0.78,>0.83$, and $>0.82$, respectively, indicating similar global gene expressions (Figure $5 \mathrm{C}, \mathrm{D})$. The top 10 upregulated GO term analysis showed that genes of both 3D-PEG-ECs and 3D-alginate-ECs are enriched in the cardiovascular system development, vasculature development, blood circulation, angiogenesis, and ECM assembly (Figure 6A,B), and genes of 2D-ECs are enriched in the cell cycle and proliferation and oxidative stress response. A Venn diagram showed that the number of DEGs in both 3Dhydrogel systems was significantly higher than that of the traditional 2D culture system. These results indicated that a $3 \mathrm{D}$ 
A

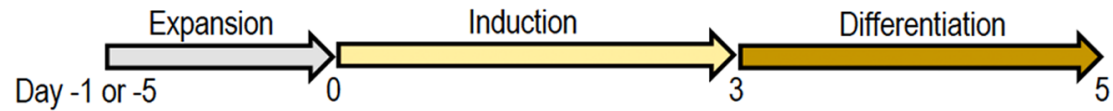

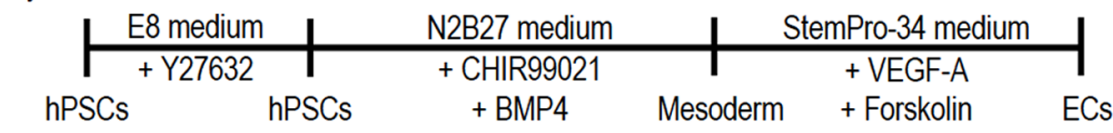

$B$
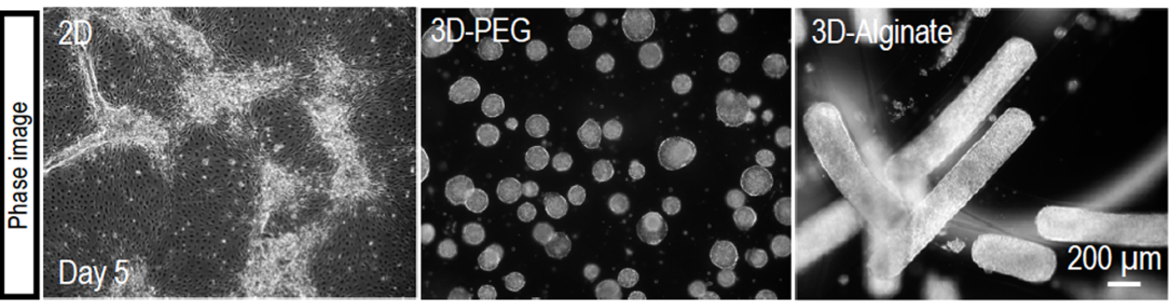

C
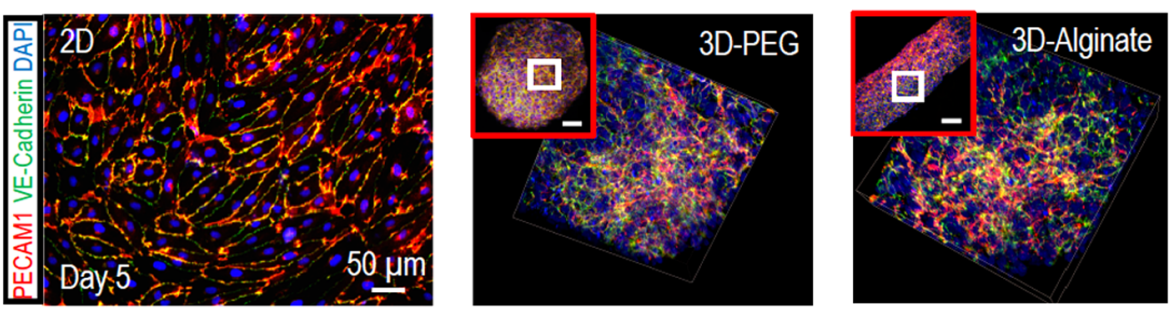

D
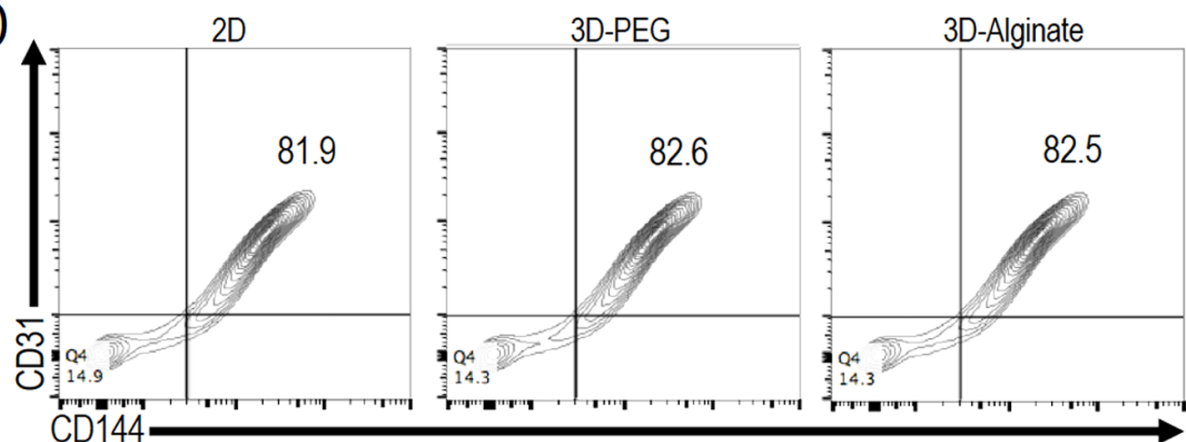

E
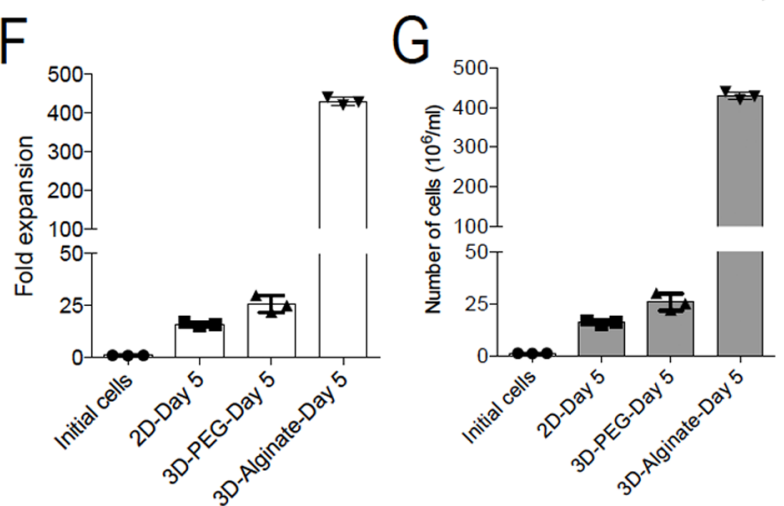

Figure 3. Comparison of hPSC-derived ECs in three culture systems. (A) Schematic illustration of the EC differentiation protocol. (B) Phase images of hPSC-ECs on day 5 in 2D, 3D-PEG, and 3D-alginate culture systems. Scale bar, $200 \mu \mathrm{m}$. (C) Immunostaining analysis of EC markers PECAM1 (or CD31) and VE-cadherin (or CD144) on day 5 cells. Scale bar, $50 \mu \mathrm{m}$. (D,E) Flow cytometry analysis of EC markers CD31 and CD144 on day 5 cells. $(\mathrm{F}, \mathrm{G})$ When seeded at $1.0 \times 10^{6}$ cells $/ \mathrm{mL}$, about 16-, 25 -, and 400 -fold expansion, yielding $\sim 1.6 \times 10^{7} \mathrm{ECs} / \mathrm{mL}, 2.0 \times 10^{7}$ ECs $/ \mathrm{mL}$ PEG hydrogel, and $\sim 4.0 \times 10^{8} \mathrm{ECs} / \mathrm{mL}$ alginate hydrogel, are produced in $2 \mathrm{D}$, 3D-PEG, and 3D-alginate culture systems on day 5 , respectively.

environment promoted functional EC formation, while 2D culturing induced ECs to have a proliferative phenotype. Our results were consistent with the literature. ${ }^{38,39}$

Detailed gene expression analysis with the RNA-Seq data showed the following differences among 3D-PEG-ECs, 3D-
alginate-ECs, and 2D-ECs: (a) both hydrogel systems had similar expressions of ECM genes, including collagens: COL23A1, COL20A1, COL3A1, COL11A2, COL6A6, COL6A3, COL14A1, COL24A1, COL4A4, COL16A1, COL25A1, COL27A1, COL5A1, and COL6A5, but different 
A
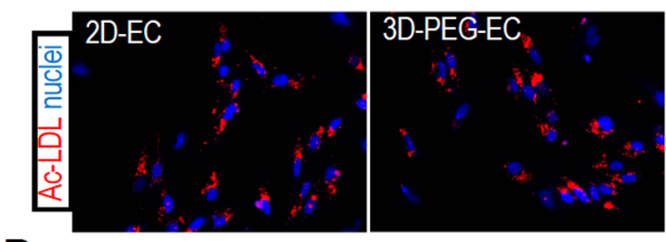

B

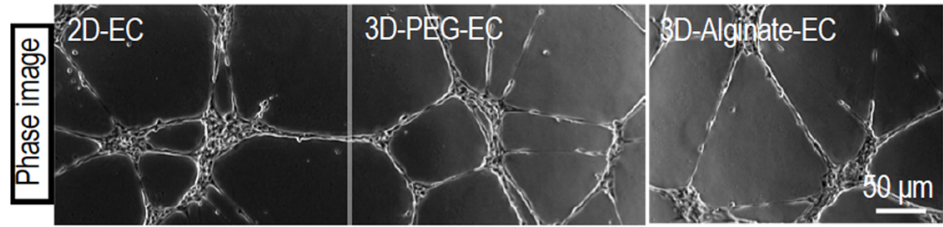

C

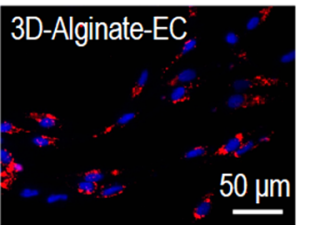

$50 \mu \mathrm{m}$

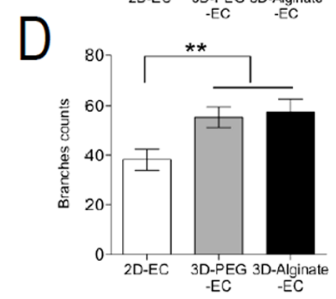

E
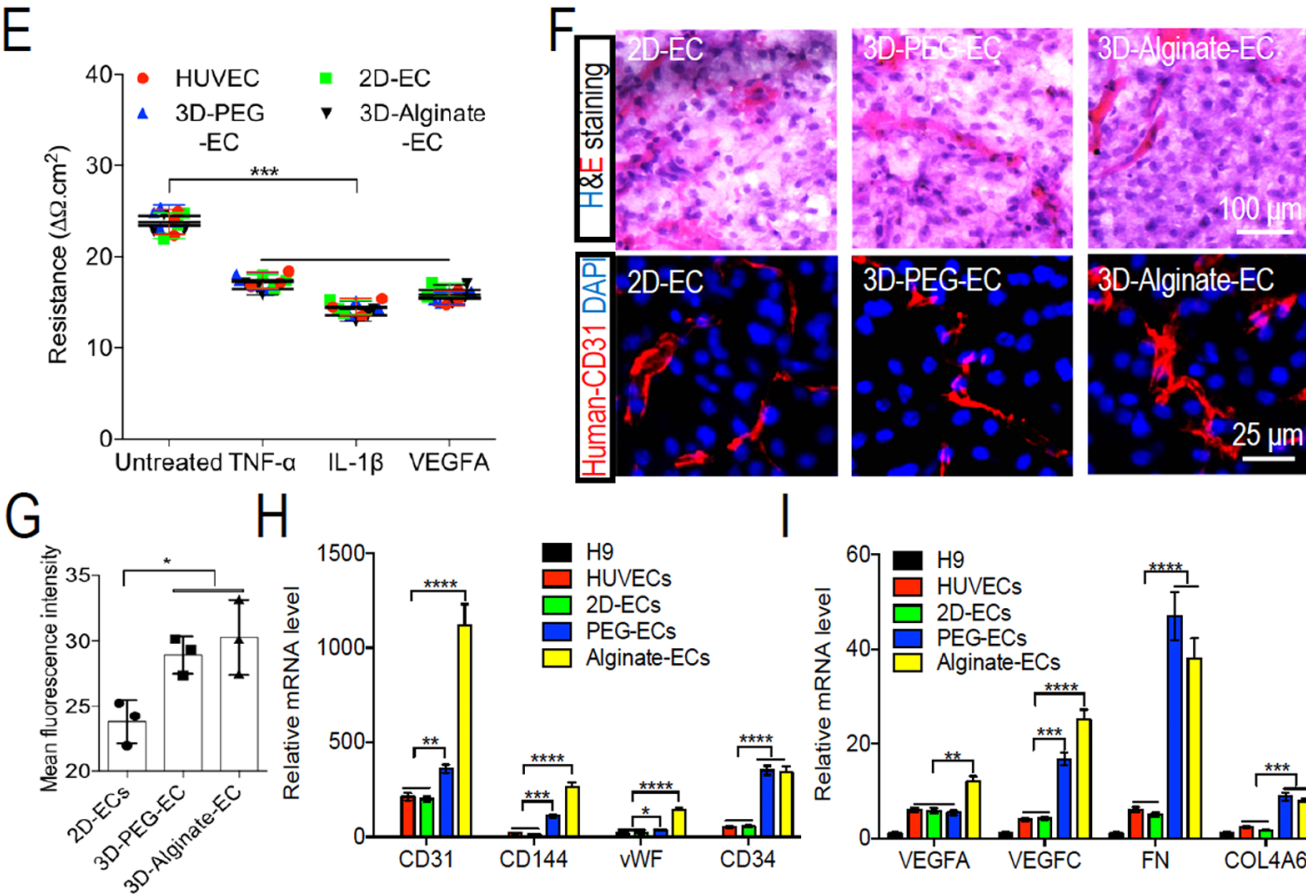

$\mathrm{H}$
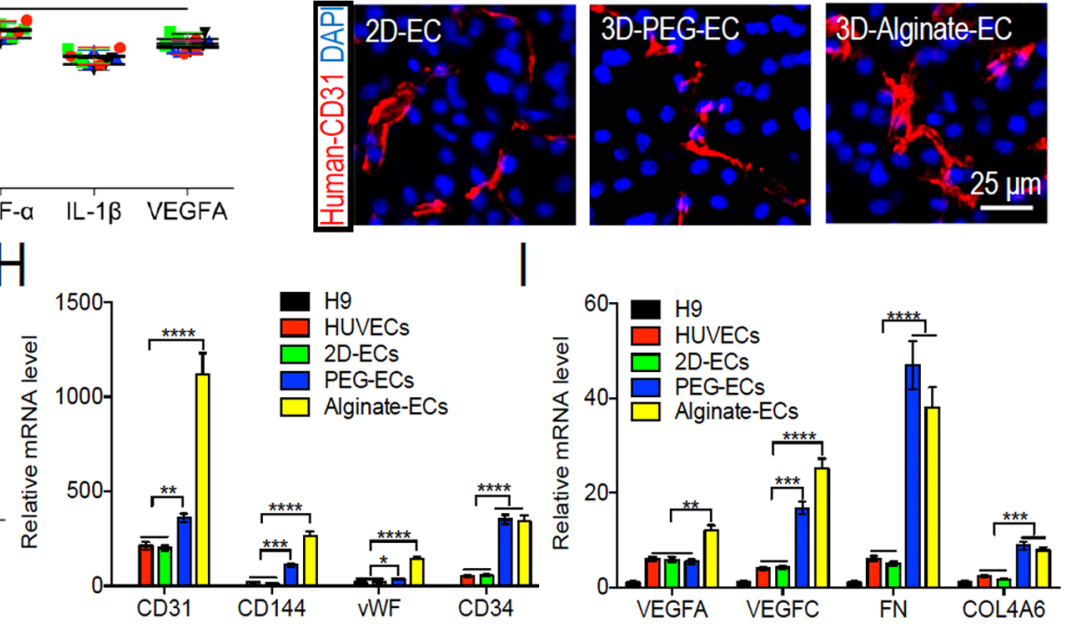

Figure 4. Functional properties of ECs derived from three culture systems. (A) Uptake by fluorescence-labeled acetylated LDL (Ac-LDL). Scale bar, $50 \mu \mathrm{m}$. (B-D) All ECs form a tubular network when plated on Matrigel for $24 \mathrm{~h}$. The tube length (mm/field) (C) and branches (D) are calculated using the Angiogenesis Analyzer of ImageJ software. Scale bar, $50 \mu \mathrm{m}$. ${ }^{*} p<0.05, * * p<0.01$. (E) TEER properties of HUVECs, 3Dalginate-ECs, 3D-PEG-ECs, and 2D-ECs (either untreated or treated with $100 \mathrm{ng} / \mathrm{mL}$ TNF- $\alpha$ or $100 \mathrm{ng} / \mathrm{mL} \mathrm{IL}-1 \beta$ or $100 \mathrm{ng} / \mathrm{mL}$ VEGF-A) are similar. $* * * p<0.001$. $(\mathrm{F}, \mathrm{G})$ When transplanted subcutaneously with a Matrigel matrix, all ECs form vascular structures, as indicated by H\&E staining and immunostaining analysis. Scale bar, 100 and $25 \mu \mathrm{m}$. (H,I) qRT-PCR shows that 3D-PEG-ECs and 3D-alginate-ECs have higher expressions of the key genes related to ECs compared with 2D-ECs or HUVECs. $*_{p}<0.05, * * p<0.01, * * * p<0.001, * * * * p<0.0001$.

expressions in COL21A1; laminins: LAMC3, but different expressions in LAMB3, LAMB4, LAMC2, and LAMA4; other ECM components: DCN, THBS2, HSPG2, FN1, THSD1, and VWF; proteases: MMP9, MMP23B, MMP24, and MMP16, but different expressions in MMP17 and MMP3; and integrins: ITGA2, ITGB2, ITGB3, ITGA2B, ITGA6, ITGA10, ITGB8, and ITGA9, but different expressions in ITGA11 (Figure 6CG); 2D-ECs had higher expressions of ECM genes, including collagens: COL11A1, COL8A2, COL2A1, and COL12A1; laminins: LAMC1; other ECM components: EFEMP1, NTN1, and FBN1; proteases: MMP11, MMP1, TIMP3, TIMP2, MMP15, MMP2, and MMP19; and integrins: ITGAL, ITGB6, ITGA7, ITGB4, ITGB5, ITGAV, ITGAX, and ITGB7 (Figure $6 \mathrm{C}-\mathrm{G})$. (b) Both hydrogel systems had higher expressions of genes for EC-secreted factors, including MMP9, IGF1, TNFRSF10C, VEGFA, CCL5, IGFBP1, IGFBP2, CXCL16,
ANGPT1, FGF10, ANGPT2, IL1B, VEGFB, CDH5, VEGFC, and PECAM1, but different expressions in IL6, ANG, CXCL10, TGFA, CXCL11, IL8, FGF2, IL7, HBEGF, PDGFA, and EGF (Figure 6H); 2D-ECs had higher expressions of genes for EC-secreted factors, including CXCL1, CCL7, CTGF, CXCL2, CXCL6, HGF, CCL2, TIMP2, CXCL5, and FGF1 (Figure 6H). (c) Both hydrogel systems had higher expressions of genes for glycolysis, including ENO2, GPI, PGK2, PGK1, PGAM2, PGM2, ALDOB, and PFKL (Figure 6I), and angiogenesis (Figure $6 \mathrm{~J})$. (d) 2D-ECs had higher gene expressions in the cell cycle and proliferation (Figure $6 \mathrm{~K}$ ).

\section{DISCUSSION}

hPSC-derived ECs are produced either in a traditional 2D culture or in a $3 \mathrm{D}$ suspension culture. However, because the 
A

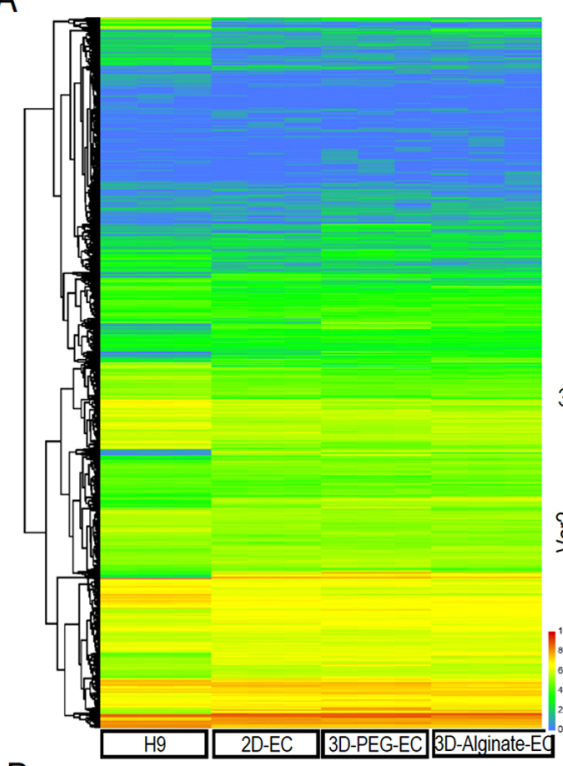

B
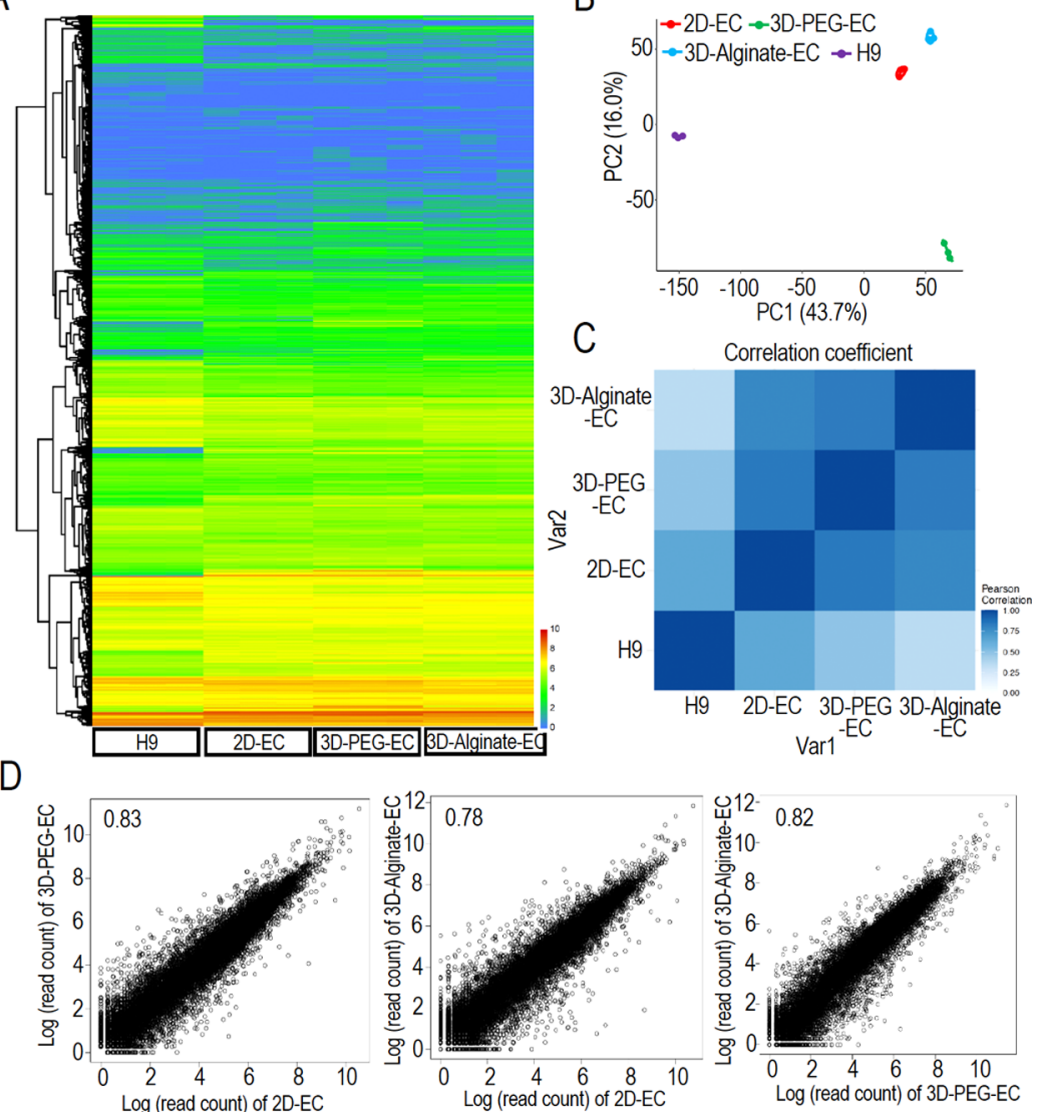

Figure 5. Whole transcriptome analysis of 3D-alginate-ECs, 3D-PEG-ECs, and 2D-ECs derived from H9s. (A,B) Global heat map of expressed genes and PCA of all ECs. (C) Heat map representation of the Spearman rank correlation coefficient between methods. Correlation color key goes from white ( 0 , no correlation) to blue (1, perfect correlation). (D) Scatterplot in the log scale of gene expression for all ECs. Three biological replicates are used for each sample.

culturing conditions are very different from the physiologically relevant microenvironments, both cultures have difficulty in generating large numbers of high-quality ECs for drug discovery, tissue engineering, and cell therapies. ${ }^{18,53-56}$ For $2 \mathrm{D}$ culturing, it is only considered suitable for preparing smallscale cells due to its labor-, space-, and reagent-consumption requirements. ${ }^{40}$ For 3D suspension culturing, it results in large cell agglomerates due to frequent cell-to-cell interactions (e.g., hPSCs $)^{40}$ and the insufficient mass transport to cells located at the center of the large agglomerates (e.g., $>400 \mu$ m diameter), leading to low cell production, cell death, and spontaneous differentiation. ${ }^{40}$ In summary, the large cell aggregation and the critical shear force make it difficult to culture hPSCs and their derivatives in large scales in 3D suspension culturing. Although moving the 2D cell culture to 3D cell culture (e.g., fibrin or Matrigel) is an attractive approach for scaling up production, ${ }^{44,57}$ they also highlight significant challenges for the 3D hPSC culture. Animal-derived Matrigel has some challenges, including the variation between the production batches, undefined composition, and lack of controlled physical properties, and it also influences the gene expression of cells. In addition, both Matrigel and fibrin are not easy to manipulate for the cell culture and have limited reproducibility and scalability and the risks for pathogen and immunogen transfer; thus, they are not considered as good manufacturing practice cell production.

Based on our previous studies, we have managed to expand and differentiate hPSCs in 3D-PEG hydrogel ${ }^{51}$ and 3D- alginate hydrogel cultures. ${ }^{50}$ In this article, we made a detailed comparative study for hPSC-ECs derived from the traditional 2D culture, 3D-PEG hydrogel culture, and 3D-alginate hydrogel culture. We found that both hydrogel systems had similar results as hPSC-derived ECs in conventional cell culture methods and had similar whole transcriptional gene expression patterns. However, the high culture efficiency makes the 3D-alginate hydrogel culture system very attractive for large-scale and high-quality cell production. The 3Dalginate hydrogel culture system eliminates both the cell agglomeration and shear force and their related side effects. hPSC-derived ECs could be produced in the alginate hydrogel system with a high culture efficiency and high yield $(\sim 5.0 \times$ $10^{8}$ cells $/ \mathrm{mL}$ ). About 250 times of the yield in 3D suspension culturing and $\sim 25$ times of the yield in the 3D-PEG hydrogel culture system was achieved. ${ }^{23,48}$ Alginates provide several advantages for biomedical applications: (1) they are non-toxic and clinical-grade materials, thus unlikely to cause any immune concerns; ${ }^{58}(2)$ they can be instantly cross-linked with $\mathrm{Ca}^{2+}$ ions without harming cells; (3) they are affordable and available; ${ }^{58}$ (4) the resultant hydrogel tubes can be easily dissolved with $0.5 \mathrm{mM}$ EDTA solution to release the cell products; (5) they allow quick nutrient diffusion through the alginate hydrogel shell; (6) they are mechanically and chemically stable, allowing long-term and large-scale cell cultures; and (7) they are transparent, allowing for optical monitoring. ${ }^{58}$ In particular, frequent passaging is the drawback for large-scale cell production since it is time-, labor-, and 


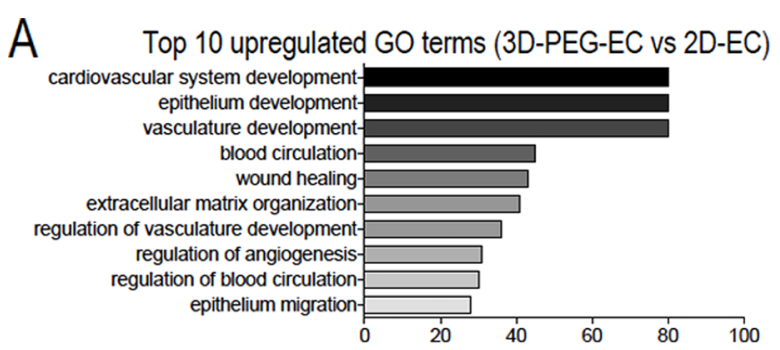

C 2D-EC

Up-regulated gene counts
271

334

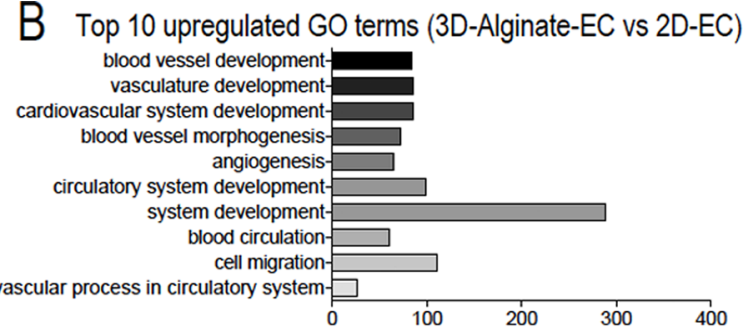

Down-regulated gene counts
3D-PEG-EC
318

325

1704
234

434
221
448
567

452
3D-Alginate-EC
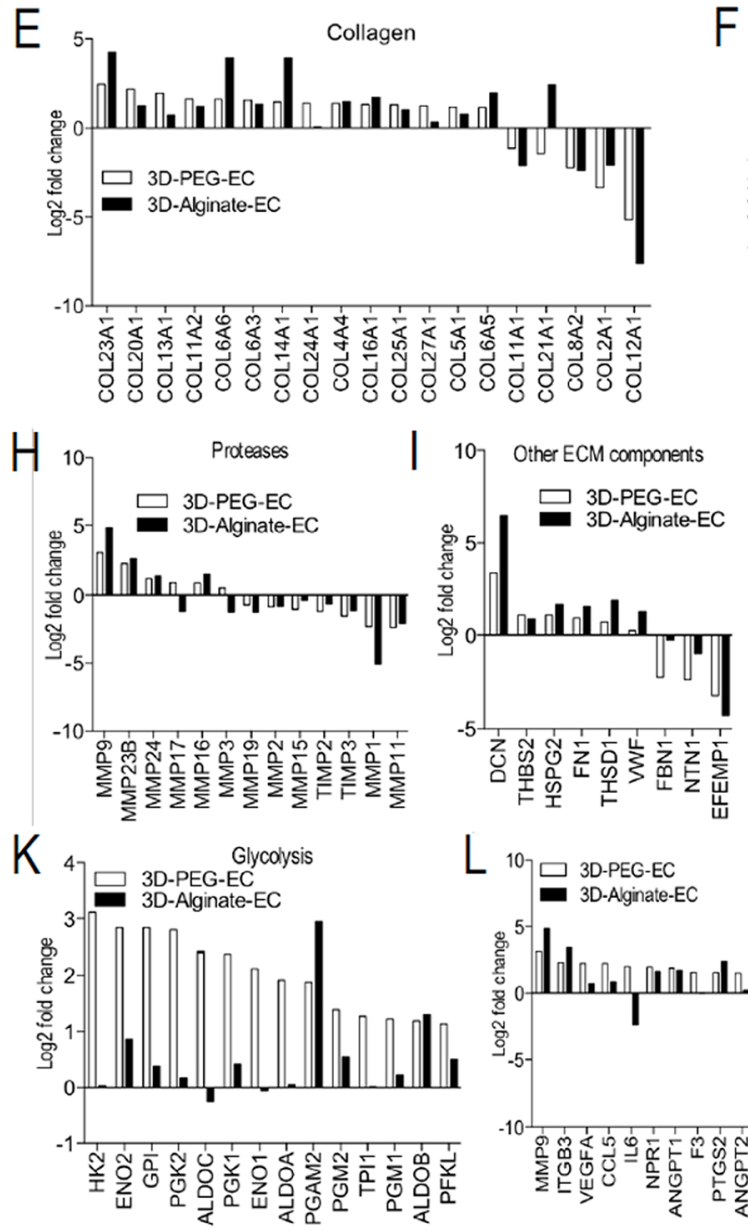
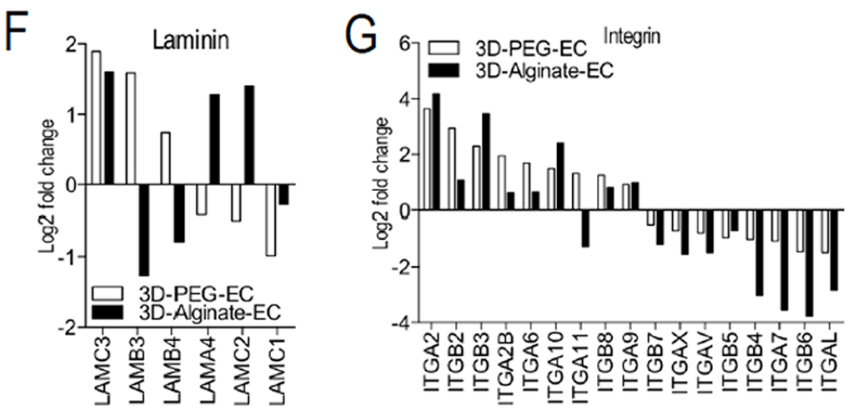

J 107

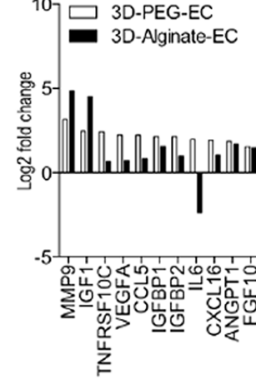

EC secretome
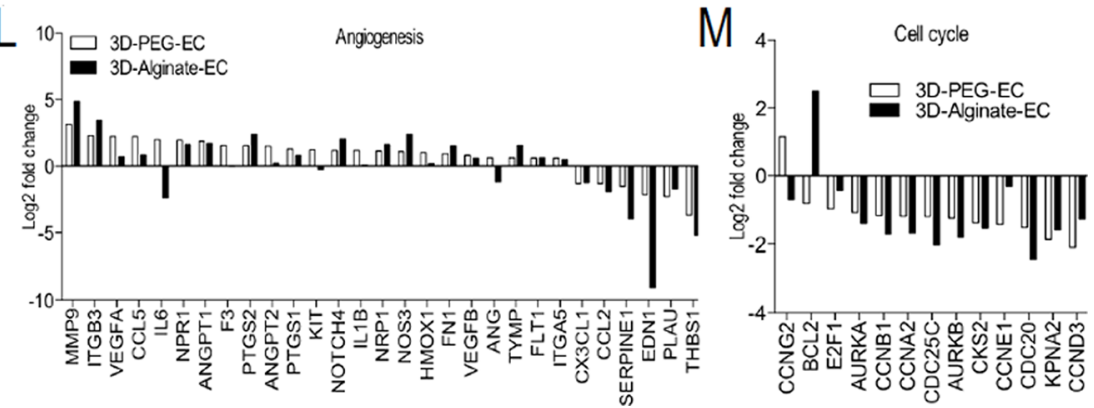

Figure 6. Differential gene expression analysis among all ECs derived from H9s. (A,B) Top 10 upregulated GO terms in the 3D-PEG-EC and 3Dalginate-EC groups compared with 2D-ECs, respectively. (C,D) Venn diagram showing the upregulated and downregulated gene counts in 2D-EC, 3D-PEG-EC, and 3D-alginate-EC groups. (E-I) $\log _{2}$ (expression level in 3D-PEG-ECs or 3D-alginate-ECs/expression level in 2D-ECs) of extracellular matrix genes. $(\mathrm{J}-\mathrm{M}) \log _{2}$ (expression level in 3D-PEG-ECs or 3D-Alginate-ECs/expression level in 2D-ECs) of genes related to EC secretome $(\mathrm{J})$, glycolysis $(\mathrm{K})$, angiogenesis $(\mathrm{L})$, and proliferation $(\mathrm{M})$. 
reagent-consuming and poses the risk of contamination and culture failure, resulting in the loss of large numbers of cells and causing difficulties during automation. In addition, according to our data, we demonstrated that the $3 \mathrm{D}$ microenvironment could enhance ECM genes, key genes, and cellular factors related to ECs by RNA sequencing (Figure 6) and qRT-PCR analysis (Figure 5G,H), which benefits the production of functional ECs (Figure 5A-F). Thus, the 3D environment offers many features that benefit the hPSC biology and culture, including supporting cell growth and differentiation, prevention of large cell aggregate formation, isolation of cells from shear forces, and sufficient porosity for nutrient diffusion.

\section{CONCLUSIONS}

In summary, we made a detailed comparative study for hPSCEC generation from the 2D, 3D-PEG hydrogel, and 3Dalginate hydrogel culture systems and demonstrated that hPSC-ECs generated from both hydrogel systems displayed a functional phenotype, while 2D-ECs showed a proliferative phenotype, according to their gene expressions related to ECs and functional properties. Finally, taking all aspects into consideration, including the cell yield and quality, the number of cell passages, cost-effectiveness, scalable production, physiologically relevant microenvironment, time-/labor-/ space-/reagent-consumption, gene expression, and functional properties, we believe that the $3 \mathrm{D}$-alginate hydrogel culture system will become a versatile culture system and will make hPSCs or their derivatives broadly available for various applications.

\section{EXPERIMENTAL SECTION}

Routine Cell Culture. H9 hESCs (\#WA09, WiCell) were purchased from the WiCell Research Institute. hPSCs were cultured in well-plate pre-coated with Matrigel (\#354277, BD Biosciences) in the Essential 8 medium (E8, \#A1517001, Invitrogen). Cells were passaged every 4 days with $0.5 \mathrm{mM}$ EDTA (\#AM9260G, Invitrogen). The medium was changed daily. Cells were routinely checked for the expression of pluripotency markers, OCT4 and NANOG, their capability to form teratomas in immunodeficient mice, their karyotypes, and bacterial or mycoplasma contamination. HUVECs (\#00191027, Lonza) were obtained from Lonza.

Culturing hPSCs in 3D PNIPAAm-PEG Hydrogels. The method for the hPSC culture in 3D PNIPAAm-PEG hydrogels has been described in our previous publications. ${ }^{23,51}$ Briefly, hPSCs were dissociated into single cells with Accutase (\#A1110501, Life Technologies), mixed with 10\% PNIPAAm-PEG solution dissolved in E8 medium on ice, cast on the tissue culture plate, and then incubated at $37{ }^{\circ} \mathrm{C}$ for $10 \mathrm{~min}$ to form hydrogels, before warm E8 medium containing a 10 $\mu \mathrm{M}$ ROCK inhibitor (RI, Y-27632, \#Y5301, LC Laboratories) was added. To passage cells, the medium was removed after culturing cells for 5 days, and pre-cold PBS was added to dissolve the hydrogel. Cell spheroids were collected by spinning at $100 \mathrm{~g}$ for $3 \mathrm{~min}$. Cells were incubated in Accutase at $37^{\circ} \mathrm{C}$ for $10 \mathrm{~min}$ and dissociated into single cells.

Extruding Alginate Hydrogel Tubes and Culturing hPSCs. Alginate hydrogel tubes are processed as described in our previous publication. ${ }^{48}$ Briefly, a custom-made microextruder was used to process the alginate tubes. A hyaluronic acid (Lifecore Biomedical, \#HA700K-5) solution containing single cells and an alginate (Wako Chemicals, 80-120 cp, \#19413321) solution were pumped into the central and side channels of the home-made micro-extruder, respectively, and extruded into a $\mathrm{CaCl}_{2}$ buffer $(100 \mathrm{mM})$ to make alginate hydrogel tubes. Subsequently, $\mathrm{CaCl}_{2}$ buffer was replaced by the cell culture medium. The method for the hPSC culture in alginate hydrogel tubes has been described in our previous publication. $^{48}$

Making hPSC-ECs in 2D Culture, 3D-PEG Hydrogel, or 3D-Alginate Hydrogel Systems. For EC differentiation in 2D culture, hPSCs were dissociated into single cells with Accutase and plated on Matrigel-coated plates at a density of 40,000 cells $/ \mathrm{cm}^{2}$ in E8 medium with $10 \mu \mathrm{M}$ RI. After $24 \mathrm{~h}$, the medium was replaced with a differentiation medium, consisting of a 1:1 mixture of DMEM/F12 (\#SH30004.04, HyClone) with Glutamax-I (\#35050061, Life Technologies) and Neurobasal Medium (\#21103049, Life Technologies) supplemented with N2 (\#17502048, Life Technologies) and B27 minus vitamin A (\#12587010, Life Technologies), with $8 \mu \mathrm{M}$ CHIR99021 (\#C6556, LC Laboratories) and $25 \mathrm{ng} / \mathrm{mL}$ BMP4 (\#314BP010, R\&D Systems). After 3 days, the differentiation medium was replaced by an EC induction medium consisting of StemPro-34 SFM medium (\#10639011, Life Technologies) supplemented with $200 \mathrm{ng} / \mathrm{mL}$ VEGFA (\#100-20, PeproTech) and $2 \mu \mathrm{M}$ Forskolin (\#F3917, Sigma). On day 6, ECs were replated on human fibronectin (\#F1141, Sigma)-coated dishes for EC expansion with a medium consisting of EGM-2 medium (\#CC3162, Lonza) supplemented with $50 \mathrm{ng} / \mathrm{mL}$ VEGFA.

For ECs differentiation in 3D-PEG or 3D-alginate system, single hPSCs were encapsulated in both hydrogels $\left(1.0 \times 10^{6}\right.$ cells $/ \mathrm{mL}$ hydrogel) and cultured in E8 medium for 5 days. Then, the E8 medium was removed and replaced with an EC differentiation medium. After 3 days, the differentiation medium was replaced by an EC induction medium. The induction medium was changed after 1 day. On day 10, cell masses were collected for the following analysis.

Immunostaining. For 2D immunostaining, the cells were fixed with $4 \%$ paraformaldehyde (PFA) at room temperature for $20 \mathrm{~min}$, permeabilized with $0.25 \%$ Triton X-100 for $30 \mathrm{~min}$, and blocked with $5 \%$ donkey serum for $1 \mathrm{~h}$ before being incubated with primary antibodies (Table S1) at $4{ }^{\circ} \mathrm{C}$ overnight. After extensive washing, secondary antibodies (Table S1) and $10 \mu \mathrm{M} \quad 4^{\prime}$,6-diamidino-2-phenylindole (DAPI) in $2 \%$ bovine serum albumin (BSA) were added and incubated at room temperature for $4 \mathrm{~h}$. Cells were washed with PBS three times before imaging with an A1 confocal microscope. For 3D immunostaining, cell masses were fixed for $30 \mathrm{~min}$ and then incubated with PBS $+0.25 \%$ Triton X-100 $+5 \%$ (vol/vol) goat serum + primary antibodies at $4{ }^{\circ} \mathrm{C}$ for 48 h. After extensive washing, secondary antibodies in $2 \%$ BSA were added and incubated at $4{ }^{\circ} \mathrm{C}$ for $24 \mathrm{~h}$. Cells were washed with PBS three times before the imaging with a confocal microscope.

Flow Cytometry. The harvested cells were dissociated into single cells with Accutase and then fixed with 4\% PFA at room temperature for $20 \mathrm{~min}$. Single cells were stained with primary antibodies (Table S1) at $4{ }^{\circ} \mathrm{C}$ overnight. After washing the cells three times with $1 \%$ BSA in PBS, secondary antibodies were added and incubated at room temperature for $2 \mathrm{~h}$. Cells were washed with $1 \%$ BSA in PBS and analyzed using a Cytek $\mathrm{DxP} 10$ flow cytometer. Single-color and isotype controls served as compensation and negative gating, respectively. 
Quantitative Real-Time PCR. Total RNA for qPCR and RNA sequencing were extracted from 2D-ECs on day 6 and from PEG-ECs and alginate-ECs on day 10 of the differentiation using Trizol (\#15596018, Invitrogen), according to the manufacturer's instructions. Reverse transcription was done with a Maxima First Strand cDNA Synthesis Kit (\#K1642, Life Technologies). Quantitative real-time PCR was carried out in an Eppendorf MasterCycler RealPlex4 (ThermoFisher Scientific) using the Power SYBR Green PCR Master Mix (\#4367659, ThermoFisher), according to the manufacturer's instructions. The data were normalized to the endogenous GAPDH. Primer sequences are listed in Table S2.

Tube Formation. A volume of $200 \mu \mathrm{L}$ of Matrigel was aliquoted into each well of a 12-well plate and incubated for 30 min at $37{ }^{\circ} \mathrm{C}$ to allow the gel to solidify. Then, 80,000 hPSCECs were seeded onto the matrix and cultured for $24 \mathrm{~h}$ at 37 ${ }^{\circ} \mathrm{C}$ until image acquisition. Cells were fixed with $2 \%$ PFA for $10 \mathrm{~min}$ and analyzed using a Zeiss fluorescence microscope.

Uptake of Dil-Ac-LDL. Cells were incubated with $2.5 \mathrm{~g} /$ mL DiI-Ac-LDL-Alexa597 (\#L3484, Molecular Probes/Life Technologies) in StemPro-34 medium for $4 \mathrm{~h}$ at $37{ }^{\circ} \mathrm{C}$. Thereafter, cells were washed three times with PBS and fixed with 4\% PFA for 10 min. DNA was counterstained with DAPI. The cellular uptake of DiI-Ac-LDL-Alexa 597 was visualized with a fluorescence microscope (Zeiss).

Trans-endothelial Electrical Resistance. hPSC-ECs were seeded at a density of $1.0 \times 10^{6}$ cells $/ \mathrm{mL}$ on 24 -well cell culture inserts $(0.4 \mu \mathrm{M}$ pore size, cat \# 3470, Corning) coated with fibronectin. Cells were grown for $72 \mathrm{~h}$ in EGM-2 medium. The medium was then changed to a starvation medium (basal EBM medium $+0.5 \%$ fetal bovine serum) with or without vascular permeability factors $(100 \mathrm{ng} / \mathrm{mL}$ TNF- $\alpha$ (cat \# 300-01A, Peprotech), IL-1 $\beta$ (cat \# 200-01B, Peprotech), and $100 \mathrm{ng} / \mathrm{mL}$ VEGF-A) for $30 \mathrm{~h}$. TEER was recorded using the Digital AC/DC clamp meter (cat \# MS2101, MASTECH). This experiment was performed in triplicate for each condition and repeated three times. Results are depicted as the steadystate TEER values with the blank filter subtracted.

Matrigel Plug Assay. Animal procedures were performed in accordance with an IACUC-approved protocol reviewed by the University of Nebraska-Lincoln Animal Care and Use Committee. Female 6- to 8-week-old SCID mice (Charles River Laboratory) were used. Differentiated ECs were added to the Matrigel mixture to a final concentration of 10 million cells $/ \mathrm{mL}$. The Matrigel mixture $(300 \mu \mathrm{L})$ was then immediately engrafted subcutaneously into the dorsal flank of the mouse. Two implants were engrafted per animal. Implants were recovered after 14 days, and then, the implants were excised. They were fixed in 4\% PFA. H\&E staining and immunostaining were performed to analyze the tube formation potential in vivo.

RNA Sequencing and Data Analysis. Total RNA of day 6 ECs cultured in 2D culture $(n=3)$ and day 10 ECs cultured in PEG $(n=3)$ and alginate hydrogel systems $(n=3)$ were prepared with an RNeasy mini kit (cat \# 74104 QIAGEN) according to the manufacturer's instruction. Libraries were prepared with a TruSeq Stranded mRNA Library Prep Kit and sequenced with Illumina NextSeq 500. 20 million 75 bp paired-end reads were generated for each sample. Methods for the data processing, heatmap generating, PCA analysis, GO terms, and differential gene expression analysis have been described in previous publications. ${ }^{48,51}$ A sample size of three and three biological replicates were used for each group.
Statistical Analysis. The data are presented as the mean \pm standard deviation (SD) from three independent experiments. We used an unpaired $t$-test to compare two groups and oneway ANOVA to compare more than two groups. A sample size of three was selected so that at a significance level of 0.05 , there was at least $95 \%$ chance of detecting two SD's difference in the outcome between the groups. All data were processed using GraphPad Prism 8 (GraphPad Software, Inc., La Jolla, CA).

Accession Numbers. The accession numbers for the data reported in this article are GEO: GSE99776 and GSE109683.

\section{ASSOCIATED CONTENT}

Supporting Information

The Supporting Information is available free of charge at https://pubs.acs.org/doi/10.1021/acsomega.0c06187.

Antibodies and real-time PCR primers used in this study (PDF)

\section{AUTHOR INFORMATION}

\section{Corresponding Authors}

Yuguo Lei - Department of Chemical and Biomolecular Engineering, University of Nebraska-Lincoln, Lincoln, Nebraska 68588, United States; 이이.org/0000-00027682-6912; Phone: 402-472-5313; Email: ylei14@ unl.edu; Fax: 402-472-6989

Zhangmin Wu - Department of Vascular Surgery, Beijing Anzhen Hospital of Capital Medical University, Beijing Institute of Heart Lung and Blood Vessel Diseases, Beijing 100029, China; Phone: +86 (010) 64456353;

Email: zhangmin_wu@sina.com

Haishuang Lin - Department of Chemical Biology, School of Pharmaceutical Sciences, Peking University, Beijing 100191, China; 이잉.org/0000-0002-2601-3278; Phone: +86 (010) 82805091; Email: hlin9@bjmu.edu.cn

\section{Authors}

Zhanqi Wang - Department of Vascular Surgery, Beijing Anzhen Hospital of Capital Medical University, Beijing Institute of Heart Lung and Blood Vessel Diseases, Beijing 100029, China

Fuxing Zuo - Department of Neurosurgery, National Cancer Center/National Clinical Research Center for Cancer/Cancer Hospital, Chinese Academy of Medical Sciences and Peking Union Medical College, Beijing 100021, China

Qing Liu - Department of Obstetrics, Beijing Obstetrics and Gynecology Hospital Capital Medical University, Beijing 100006, China

Xuesheng Wu - Department of Chemical Biology, School of Pharmaceutical Sciences, Peking University, Beijing 100191, China

Qian Du - Department of Biological Systems Engineering, University of Nebraska-Lincoln, Lincoln, Nebraska 68588, United States

Complete contact information is available at:

https://pubs.acs.org/10.1021/acsomega.0c06187

\section{Author Contributions}

IIZ.W., F.Z., Q.L., and X.W. contributed equally to this work.

Notes

The authors declare no competing financial interest. 


\section{ACKNOWLEDGMENTS}

This work was supported by the National Natural Science Foundation of China (grant nos. 82000449 and 81701262) and Capital Medical University (no. 16JL90).

\section{REFERENCES}

(1) Richards, O. C.; Raines, S. M.; Attie, A. D. The Role of Blood Vessels, Endothelial Cells , and Vascular Pericytes in Insulin Secretion and Peripheral Insulin Action. Endocr. Rev. 2010, 31, 343-363.

(2) Carmeliet, P. Cardiovascular Biology: Creating Unique Blood Vessels. Nature 2001, 412, 868-869.

(3) Leung, O.; Zhou, B.; Lui, K. Vascular Development and Regeneration in the Mammalian Heart. J. Cardiovasc. Dev. Dis. 2016, 3, 23.

(4) Patsch, C.; Challet-Meylan, L.; Thoma, E. C.; Urich, E.; Heckel, T.; O’Sullivan, J. F.; Grainger, S. J.; Kapp, F. G.; Sun, L.; Christensen, K.; Xia, Y.; Florido, M. H. C.; He, W.; Pan, W.; Prummer, M.; Warren, C. R.; Jakob-Roetne, R.; Certa, U.; Jagasia, R.; Freskgård, P.O.; Adatto, I.; Kling, D.; Huang, P.; Zon, L. I.; Chaikof, E. L.; Gerszten, R. E.; Graf, M.; Iacone, R.; Cowan, C. a. Generation of Vascular Endothelial and Smooth Muscle Cells from Human Pluripotent Stem Cells. Nat. Cell Biol. 2015, 17, 994-1003.

(5) Medina, R. J.; O’Neill, C. L.; Humphreys, M. W.; Gardiner, T. A.; Stitt, A. W. Outgrowth Endothelial Cells: Characterization and Their Potential for Reversing Ischemic Retinopathy. Retina 2010, 51, 5906-5913.

(6) Moubarik, C.; Guillet, B.; Youssef, B.; Codaccioni, J.-L.; Piercecchi, M.-D.; Sabatier, F.; Lionel, P.; Dou, L.; Foucaultbertaud, A.; Velly, L.; Dignat-george, F.; Pisano, P. Transplanted Late Outgrowth Endothelial Progenitor Cells as Cell Therapy Product for Stroke. Stem Cell. Rev. Rep. 2011, 7, 208-220.

(7) Schwarz, T. M.; Leicht, S. F.; Radic, T.; Rodriguez-Arabaolaza, I.; Hermann, P. C.; Berger, F.; Saif, J.; Böcker, W.; Ellwart, J. W.; Aicher, A.; Heeschen, C. Vascular Incorporation of Endothelial Colony-Forming Cells Is Essential for Functional Recovery of Murine Ischemic Tissue Following Cell Therapy. Arterioscler. Thromb. Vasc. Biol. 2012, 32, e13-e21.

(8) Kang, K.-T.; Coggins, M.; Xiao, C.; Rosenzweig, A.; Bischoff, J. Human Vasculogenic Cells Form Functional Blood Vessels and Mitigate Adverse Remodeling after Ischemia Reperfusion Injury in Rats. Angiogenesis 2013, 16, 773-784.

(9) Huang, X.-T.; Zhang, Y.-Q.; Li, S.-J.; Li, S.-H.; Tang, Q.; Wang, Z.-T.; Dong, J.-F.; Zhang, J.-N. Intracerebroventricular Transplantation of Ex Vivo Blood-Brain Barrier Integrity and Promotes Angiogenesis of Mice with Traumatic Brain Injury. J. Neurotrauma 2013, 30, 2080-2088.

(10) Heo, S. C.; Kwon, Y. W.; Jang, I. H.; Jeong, G. O.; Yoon, J. W.; Kim, C. D.; Kwon, S. M.; Bae, Y.-S.; Kim, J. H. WKYMVm-Induced Activation of Formyl Peptide Receptor 2 Stimulates Ischemic Neovasculogenesis by Promoting Homing of Endothelial ColonyForming Cells. Stem Cell. 2014, 32, 779-790.

(11) Stroncek, J. D.; Ren, L. C.; Klitzman, B.; Reichert, W. M. Patient-Derived Endothelial Progenitor Cells Improve Vascular Graft Patency in a Rodent Model. Acta Biomater. 2012, 8, 201-208.

(12) Hayflick, L. The Limited in Vitro Lifetime of Human Diploid Cell Strains. Exp. Cell Res. 1965, 37, 614-636.

(13) Gumbleton, M.; Audus, K. L. Progress and Limitations in the Use of in Vitro Cell Cultures to Serve as a Permeability Screen for the Blood-Brain Barrier. J. Pharm. Sci. 2001, 90, 1681-1698.

(14) Augustin-Voss, H. G.; Voss, A. K.; Pauli, B. U. Senescence of Aortic Endothelial Cells in Culture: Effects of Basic Fibroblast Growth Factor Expression on Cell Phenotype, Migration, and Proliferation. J. Cell. Physiol. 1993, 157, 279-288.

(15) van Beijnum, J. R.; Rousch, M.; Castermans, K.; Van der Linden, E.; Griffioen, A. W. Isolation of Endothelial Cells from Fresh Tissues. Nat. Protoc. 2008, 3, 1085-1091.
(16) Gui, L.; Muto, A.; Chan, S. A.; Breuer, C. K.; Niklason, L. E. Development of Decellularized Human Umbilical Arteries as SmallDiameter Vascular Grafts. Tissue Eng., Part A 2009, 15, 2665-2676.

(17) de Carvalho, J. L.; Zonari, A.; Cláudia, A.; de Paula, C.; Maria, T.; Gomes, D. A.; Goes, A. M. Production of Human Endothelial Cells Free from Soluble Xenogeneic Antigens for Bioartificial Small Diameter Vascular Graft Endothelization. BioMed Res. Int. 2015, 2015, 652474.

(18) Thomson, J. A.; Itskovitz-eldor, J.; Shapiro, S. S.; Waknitz, M. A.; Swiergiel, J. J.; Marshall, V. S.; Jones, J. M. Embryonic Stem Cell Lines Derived from Human Blastocysts. Science 1998, 282, 11451147.

(19) Yu, J.; Vodyanik, M. A.; Smuga-otto, K.; Antosiewicz-bourget, J.; Frane, J. L.; Tian, S.; Nie, J.; Jonsdottir, G. A.; Ruotti, V.; Stewart, R.; Slukvin, I. I.; Thomson, J. A. Induced Pluripotent Stem Cell Lines Derived from Human Somatic Cells. Science 2007, 318, 1917-1920.

(20) Takahashi, K.; Tanabe, K.; Ohnuki, M.; Narita, M.; Ichisaka, T.; Tomoda, K.; Yamanaka, S. Induction of Pluripotent Stem Cells from Adult Human Fibroblasts by Defined Factors. Cell 2007, 131, $861-872$

(21) Levenberg, S.; Zoldan, J.; Basevitch, Y.; Langer, R. Endothelial Potential of Human Embryonic Stem Cells. Blood 2007, 110, 806814

(22) Chen, G.; Gulbranson, D. R.; Hou, Z.; Bolin, J. M.; Ruotti, V.; Probasco, M. D.; Smuga-Otto, K.; Howden, S. E.; Diol, N. R.; Propson, N. E.; Wagner, R.; Lee, G. O.; Antosiewicz-Bourget, J.; Teng, J. M. C.; Thomson, J. A. Chemically Defined Conditions for Human IPSC Derivation and Culture. Nat. Methods 2011, 8, 424429.

(23) Lei, Y.; Schaffer, D. V. A Fully Defined and Scalable 3D Culture System for Human Pluripotent Stem Cell Expansion and Differentiation. Proc. Natl. Acad. Sci. U.S.A. 2013, 110, E5039-E5048.

(24) Nourse, M. B.; Halpin, D. E.; Scatena, M.; Mortisen, D. J.; Tulloch, N. L.; Hauch, K. D.; Torok-storb, B.; Ratner, B. D.; Pabon, L.; Murry, C. E. VEGF Induces Differentiation of Functional Endothelium from Human Embryonic Stem Cells: Implications for Tissue Engineering. Arterioscler. Thromb. Vasc. Biol. 2010, 30, 80.

(25) Li, Z.; Han, Z.; Wu, J. C. Transplantation of Human Embryonic Stem Cell-Derived Endothelial Cells for Vascular Diseases. J. Cell. Biochem. 2009, 106, 194-9.

(26) Li, Z.; Wilson, K. D.; Smith, B.; Kraft, D. L.; Jia, F.; Huang, M.; Xie, X.; Robbins, R. C.; Gambhir, S. S.; Weissman, I. L.; Wu, J. C. Functional and Transcriptional Characterization of Human Embryonic Stem Cell-Derived Endothelial Cells for Treatment of Myocardial Infarction. PLoS One 2009, 4, e8443.

(27) James, D.; Nam, H.-s.; Seandel, M.; Nolan, D.; Janovitz, T.; Tomishima, M.; Studer, L.; Lee, G.; Lyden, D.; Benezra, R.; Zaninovic, N.; Rosenwaks, Z.; Rabbany, S. Y.; Rafii, S. Expansion and Maintenance of Human Embryonic Stem Cell-Derived Endothelial Cells by TGF $\beta$ Inhibition Is Id1 Dependent. Nat. Biotechnol. 2010, 28, 161-166.

(28) Levenberg, S.; Golub, J. S.; Amit, M.; Itskovitz-Eldor, J.; Langer, R. Endothelial Cells Derived from Human Embryonic Stem Cells. Proc. Natl. Acad. Sci. U.S.A. 2002, 99, 4391-4396.

(29) Condorelli, G.; Borello, U.; De Angelis, L.; Latronico, M.; Sirabella, D.; Coletta, M.; Galli, R.; Balconi, G.; Follenzi, A.; Frati, G.; Cusella De Angelis, M. G.; Gioglio, L.; Amuchastegui, S.; Adorini, L.; Naldini, L.; Vescovi, A.; Dejana, E.; Cossu, G. Cardiomyocytes Induce Endothelial Cells to Trans-Differentiate into Cardiac Muscle: Implications for Myocardium Regeneration. Proc. Natl. Acad. Sci. U.S.A. 2001, 98, 10733-10738.

(30) Kane, N. M.; Meloni, M.; Spencer, H. L.; Craig, M. A.; Strehl, R.; Milligan, G.; Houslay, M. D.; Mountford, J. C.; Emanueli, C.; Baker, A. H. Derivation of Endothelial Cells from Human Embryonic Stem Cells by Directed Differentiation Analysis of MicroRNA and Angiogenesis in Vitro and in Vivo. Arterioscler. Thromb. Vasc. Biol. 2010, 30, 1389-1397.

(31) Vodyanik, M. A.; Bork, J. A.; Thomson, J. A.; Slukvin, I. I. Human Embryonic Stem Cell-Derived CD34+ Cells: Efficient 
Production in the Coculture with OP9 Stromal Cells and Analysis of Lymphohematopoietic Potential. Blood 2005, 105, 617-626.

(32) Cao, N.; Liang, H.; Huang, J.; Wang, J.; Chen, Y.; Chen, Z.; Yang, H.-T. Highly Efficient Induction and Long-Term Maintenance of Multipotent Cardiovascular Progenitors from Human Pluripotent Stem Cells under Defined Conditions. Cell Res. 2013, 23, 1119-1132.

(33) Palpant, N. J.; Pabon, L.; Friedman, C. E.; Roberts, M.; Hadland, B.; Zaunbrecher, R. J.; Bernstein, I.; Zheng, Y.; Murry, C. E. Generating High-Purity Cardiac and Endothelial Derivatives from Patterned Mesoderm Using Human Pluripotent Stem Cells. Nat. Protoc. 2016, 12, 15-31.

(34) Giacomelli, E.; Bellin, M.; Sala, L.; van Meer, B. J.; Tertoolen, L. G. J.; Orlova, V. V.; Mummery, C. L. Three-Dimensional Cardiac Microtissues Composed of Cardiomyocytes and Endothelial Cells CoDifferentiated from Human Pluripotent Stem Cells. Development 2017, 144, 1008-1017.

(35) Zhang, J.; Chu, L.-F.; Hou, Z.; Schwartz, M. P.; Hacker, T.; Vickerman, V.; Swanson, S.; Leng, N.; Nguyen, B. K.; Elwell, A.; Bolin, J.; Brown, M. E.; Stewart, R.; Burlingham, W. J.; Murphy, W. L.; Thomson, J. A. Functional Characterization of Human Pluripotent Stem Cell-Derived Arterial Endothelial Cells. Proc. Natl. Acad. Sci. U.S.A. 2017, 114, E6072-E6078.

(36) Lian, X.; Bao, X.; Al-Ahmad, A.; Liu, J.; Wu, Y.; Dong, W.; Dunn, K. K.; Shusta, E. V.; Palecek, S. P. Efficient Differentiation of Human Pluripotent Stem Cells to Endothelial Progenitors via SmallMolecule Activation of WNT Signaling. Stem Cell Rep. 2014, 3, 804816.

(37) Orlova, V. V.; van den Hil, F. E.; Petrus-Reurer, S.; Drabsch, Y.; Ten Dijke, P.; Mummery, C. L. Generation, Expansion and Functional Analysis of Endothelial Cells and Pericytes Derived from Human Pluripotent Stem Cells. Nat. Protoc. 2014, 9, 1514-1531.

(38) Zhang, J.; Schwartz, M. P.; Hou, Z.; Bai, Y.; Ardalani, H.; Swanson, S.; Steill, J.; Ruotti, V.; Elwell, A.; Nguyen, B. K.; Bolin, J.; Stewart, R.; Thomson, J. A.; Murphy, W. L. A Genome-Wide Analysis of Human Pluripotent Stem Cell-Derived Endothelial Cells in 2D or 3D Culture. Stem Cell Rep. 2017, 8, 907-918.

(39) Zujur, D.; Kanke, K.; Lichtler, A. C.; Hojo, H.; Chung, U.-i.; Ohba, S. Three-Dimensional System Enabling the Maintenance and Directed Differentiation of Pluripotent Stem Cells under Defined Conditions. Sci. Adv. 2017, 3, e1602875.

(40) Kropp, C.; Massai, D.; Zweigerdt, R. Progress and Challenges in Large-Scale Expansion of Human Pluripotent Stem Cells. Process Biochem. 2017, 59, 244-254.

(41) Jenkins, M. J.; Farid, S. S. Human Pluripotent Stem CellDerived Products: Advances towards Robust, Scalable and CostEffective Manufacturing Strategies. Biotechnol. J. 2015, 10, 83-95.

(42) Lei, Y.; Jeong, D.; Xiao, J.; Schaffer, D. V. Developing Defined and Scalable 3D Culture Systems for Culturing Human Pluripotent Stem Cells at High Densities. Cell. Mol. Bioeng. 2014, 7, 172-183.

(43) Steiner, D.; Khaner, H.; Cohen, M.; Even-Ram, S.; Gil, Y.; Itsykson, P.; Turetsky, T.; Idelson, M.; Aizenman, E.; Ram, R.; Berman-Zaken, Y.; Reubinoff, B. Derivation, Propagation and Controlled Differentiation of Human Embryonic Stem Cells in Suspension. Nat. Biotechnol. 2010, 28, 361-364.

(44) Serra, M.; Brito, C.; Correia, C.; Alves, P. M. Process Engineering of Human Pluripotent Stem Cells for Clinical Application. Trends Biotechnol. 2012, 30, 350-359.

(45) Wurm, F. M. Production of Recombinant Protein Therapeutics in Cultivated Mammalian Cells. Nat. Biotechnol. 2004, 22, 13931398.

(46) Kinney, M. A.; Sargent, C. Y.; Mcdevitt, T. C. The Multiparametric Effects of Hydrodynamic Environments on Stem Cell Culture. Tissue Eng., Part B 2011, 17, 249-262.

(47) Fridley, K. M.; Kinney, M. A.; Mcdevitt, T. C. Hydrodynamic Modulation of Pluripotent Stem Cells. Stem Cell Res. Ther. 2012, 3, 45.

(48) Li, Q.; Lin, H.; Du, Q.; Liu, K.; Wang, O.; Evans, C.; Christian, H.; Zhang, C.; Lei, Y. Scalable and Physiologically Relevant
Microenvironments for Human Pluripotent Stem Cell Expansion and Differentiation. Biofabrication 2018, 10, 025006.

(49) Lin, H.; Li, Q.; Lei, Y. An Integrated Miniature Bioprocessing for Personalized Human Induced Pluripotent Stem Cell Expansion and Differentiation into Neural Stem Cells. Sci. Rep. 2017, 7, 40191.

(50) Lin, H.; Du, Q.; Li, Q.; Wang, O.; Wang, Z.; Elowsky, C.; Liu, K.; Zhang, C.; Chung, S.; Duan, B.; Lei, Y. Manufacturing Human Pluripotent Stem Cell Derived Endothelial Cells in Scalable and CellFriendly Microenvironments. Biomater. Sci. 2019, 7, 373-388.

(51) Lin, H.; Du, Q.; Li, Q.; Wang, O.; Wang, Z.; Sahu, N.; Elowsky, C.; Liu, K.; Zhang, C.; Chung, S.; Duan, B.; Lei, Y. A Scalable and Efficient Bioprocess for Manufacturing Human Pluripotent Stem Cells-Derived Endothelial Cells. Stem Cell Rep. 2018, 11, 454-469.

(52) Srinivasan, B.; Kolli, A. R.; Esch, M. B.; Abaci, H. E.; Shuler, M. L.; Hickman, J. J. TEER Measurement Techniques for in Vitro Barrier Model Systems. J. Lab. Autom. 2015, 20, 107-126.

(53) Wong, C. C.; Loewke, K. E.; Bossert, N. L.; Behr, B.; De Jonge, C. J.; Baer, T. M.; Pera, R. A. R. Non-Invasive Imaging of Human Embryos before Embryonic Genome Activation Predicts Development to the Blastocyst Stage. Nat. Biotechnol. 2010, 28, 1115-1121.

(54) Kraehenbuehl, T. P.; Langer, R.; Ferreira, L. S. ThreeDimensional Biomaterials for the Study of Human Pluripotent Stem Cells. Nat. Methods 2011, 8, 731-736.

(55) Chen, K. G.; Mallon, B. S.; Johnson, K. R.; Hamilton, R. S.; Mckay, R. D. G.; Robey, P. G. Developmental Insights from Early Mammalian Embryos and Core Signaling Pathways That Influence Human Pluripotent Cell Growth and Differentiation. Stem Cell Res. 2014, 12, 610-621.

(56) Chen, K. G.; Mallon, B. S.; McKay, R. D. G.; Robey, P. G. Human Pluripotent Stem Cell Culture: Considerations for Maintenance, Expansion, and Therapeutics. Cell Stem Cell 2014, 14, 1326.

(57) McDevitt, T. C.; Palecek, S. P. Innovation in the Culture and Derivation of Pluripotent Human Stem Cells. Curr. Opin. Biotechnol. 2008, 19, 527-533.

(58) Lee, K. Y.; Mooney, D. J. Alginate: Properties and Biomedical Applications. Prog. Polym. Sci. 2012, 37, 106-126. 